\title{
The Cytoplasmic Domain of \\ Alzheimer's Amyloid Precursor Protein Is Phosphorylated at Thr654, Ser655, and Thr668 in Adult Rat Brain and Cultured Cells
}

\author{
Masaki Oishi,* Angus C. Nairn,* Andrew J. Czernik,* \\ Gloria S. Lim,* Toshio Isohara,* Samuel E. Gandy, ${ }^{+}$ \\ Paul Greengard,* and Toshiharu Suzuki* \\ *Laboratory of Molecular and Cellular Neuroscience, The Rockefeller \\ University, New York, New York, U.S.A. ' ${ }^{\dagger}$ Department of Neurology \\ and Neuroscience, New York Hospital-Cornell Medical Center, \\ New York, New York, U.S.A.
}

\begin{abstract}
Background: The cytoplasmic domain of the Alzheimer's disease amyloid precursor protein (APP) is phosphorylated in vitro at Thr654 and Ser655, and both in vitro and in intact cells at Thr668 (numbering for APP $_{695}$ isoform).

Materials and Methods: We have developed phosphorylation state-specific antibodies to each of the sites, and we have used these to analyze the phosphorylation of APP in adult rat brain and in cultured cell lines.

Results: We demonstrate that all three sites in APP are phosphorylated in adult rat brain. Phosphorylation at Thr654, Ser655, and Thr668 was also observed in several cultured cell lines. In PC12 cells, phosphorylation at Ser655 was increased more than 10 -fold by treatment with okadaic acid, a specific inhibitor of protein phos-
\end{abstract}

phatases 1 and $2 \mathrm{~A}$, but was not affected by activators of protein kinase $\mathrm{C}$. In HeLa cells, phosphorylation at Thr668 was regulated in a cell cycle-dependent manner with near-stoichiometric phosphorylation being observed at the G2/M phase of the cell cycle. In general, phosphorylation at Ser655 was found to be highest in mature APP isoforms, whereas phosphorylation of Thr668 was highest in immature APP isoforms in cultured cells.

Conclusions: The results demonstrate that phosphorylation of the cytoplasmic domain of APP occurs at Thr654, Ser655, and Thr668 under physiological conditions. The further characterization of APP phosphorylation using phosphorylation-specific antibodies may help in the elucidation of the biological function of APP.

\section{INTRODUCTION}

The principal protein component of parenchymal and cerebrovascular amyloid deposits in patients with Alzheimer's disease (AD) is the $\beta$-amyloid protein $(A \beta)$ which consists of over-

Address correspondence and reprint requests to Toshiharu Suzuki at his current address: Laboratory of Neurobiophysics, Faculty of Pharmaceutical Sciences, University of Tokyo, Tokyo, 113 Japan

Toshio Isohara's current address is Life Science Research Center, Advanced Technology Research Laboratories, Nippon Steel Corporation, 1618 Ida, Nakahara-ku, Kawasaki 211 , Japan. lapping peptides 39-43 amino acids in length $(1,2)$. Molecular cloning studies have demonstrated that $A \beta$ is derived from a large precursor protein, the Alzheimer amyloid precursor protein (APP) (3-6). APP is an integral membrane glycoprotein with a receptor-like structure (4), existing in several isoforms that arise by alternative splicing of a single gene (3-10) in many tissues. Notably, a neuron-specific isoform, $\mathrm{APP}_{695}$, does not contain the Kunitz type protease inhibitor (KPI) domain found in longer isoforms, $\mathrm{APP}_{751}$ and $\mathrm{APP}_{770}$ (7-9). In addition, each isoform exists as immature (im: N-glycosy- 
lated) and mature ( $\mathrm{m}$ : $\mathrm{N}$ - and O-glycosylated, tyrosyl-sulfated) species $(4,11)$. $A \beta$ derives from a region at the junction of the ecto- and transmembrane domains of APP (3-6). However, the molecular mechanism of $A \beta$ production is yet to be fully characterized, and the biological function of APP is unknown.

It is well known that the phosphorylation of many proteins and enzymes can modify their biological functions. Abnormal phosphorylation of tau protein is believed to be involved in the pathogenesis of $\mathrm{AD}$ (reviewed in ref. 12). Recent studies have also indicated that the processing of APP and the production of $A \beta$ is regulated by protein phosphorylation (13-15). Three consensus phosphorylation sites in the cytoplasmic domain of APP have been shown to be phosphorylated in vitro (16-18). Thr654 (numbering for $\mathrm{APP}_{695}$ isoform) and Ser655 are phosphorylated by $\mathrm{Ca}^{2+}$ /calmodulin-dependent protein kinase II (CaM kinase II), Ser655 is phosphorylated by protein kinase $\mathrm{C}$ (PKC), and Thr668 is phosphorylated by cyclin-dependent protein kinase(s). To date, only the phosphorylation of Thr668 has been demonstrated in intact cells (18), although phosphorylation of a seryl residue in the extracellular domain of APP has also been demonstrated in intact cells $(19,20)$.

It is not known if any of the three cytoplasmic domain sites are phosphorylated in brain. In the present study, we have developed three different phosphorylation state-specific antibodies that recognize APP phosphorylated at either Thr654, Ser655, or Thr668, and we have used these antibodies to demonstrate that each site is phosphorylated in adult rat brain and in cultured cell lines. These results and the further utilization of the phosphorylation state-specific antibodies may help to elucidate the physiological function of APP and may, in turn, lead to a better understanding of the pathogenesis of $\mathrm{AD}$.

\section{MATERIALS AND METHODS}

\section{Synthetic Peptides}

All APP peptides, including chemically phosphorylated peptides corresponding to sequences surrounding APP phosphorylation sites, were synthesized by the Protein/DNA Technology Center of The Rockefeller University. The amyloid precursor-like protein 2 (APLP2) cytoplasmic domain peptide, APLP2 ${ }^{\text {717-764 }}$ (numbering for APLP2 ${ }_{764}$ isoform), was synthesized by the

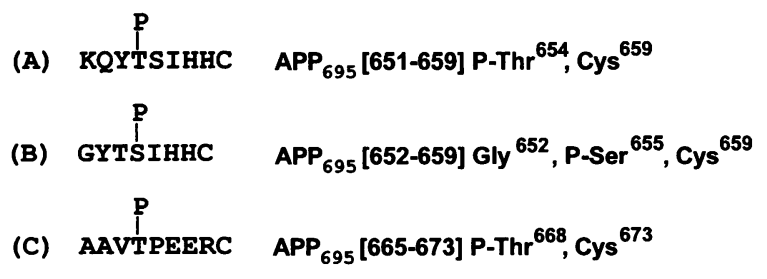

FIG. 1. Amino acid sequences of chemically phosphorylated synthetic peptide antigens used for antibody preparation

W. M. Keck Foundation Biotechnology Resource Laboratory at Yale University.

\section{Production and Specificities of Antibodies}

Polyclonal antibody G-369 was prepared against the peptide, $\mathrm{APP}^{645-694}$, which includes almost all of the cytoplasmic domain of APP (21). Polyclonal antibody G-530 was prepared against a peptide corresponding to the first 16 amino acid residues of rat $A \beta$ (plus the addition of a $C$ terminal cysteine) (DAEFGHDSGFEVRHQK[C]). Polyclonal phosphorylation state-specific antibodies were raised against chemically phosphorylated synthetic peptide antigens corresponding to APP phosphorylated at Thr654 (pAbT654), Ser655 (pAbS655), and Thr668 (pAbT668) (Fig. 1) $(22,23)$. Peptides were conjugated to Limulus hemocyanin (Sigma) with sulfo-MBS (Pierce) or glutaraldehyde and injected into rabbits. Antibodies were affinity purified with the appropriate phospho-peptide immunogen coupled to an affinity matrix. The specificity of each antibody was tested by immuno-dot blot analysis and its corresponding antigen, with unrelated phosphopeptides and dephosphopeptides used as controls. Briefly, various amounts of peptide were spotted on nitrocellulose membranes. Membranes were blocked with non-fat dry milk $(5 \% \mathrm{w} / \mathrm{v})$ in $20 \mathrm{mM}$ Tris- $\mathrm{HCl}(\mathrm{pH} \mathrm{7.4})$, probed with affinity-purified phosphorylation state-specific antibodies, and visualized with [ $\left.{ }^{125} \mathrm{I}\right]$ protein A (Amersham). Radioactivity was analyzed with a PhosphorImager (Molecular Dynamics). Antibody to the APP KPI-domain, 56.1, was a gift from Dr. R. Ramabhadran (24).

\section{Phosphorylation of APP ${ }^{645-694}$}

CaM kinase II (25) and PKC (26) were purified from rat brain. cdc2 kinase/cyclin B was obtained from New England Biolabs. For phosphorylation 

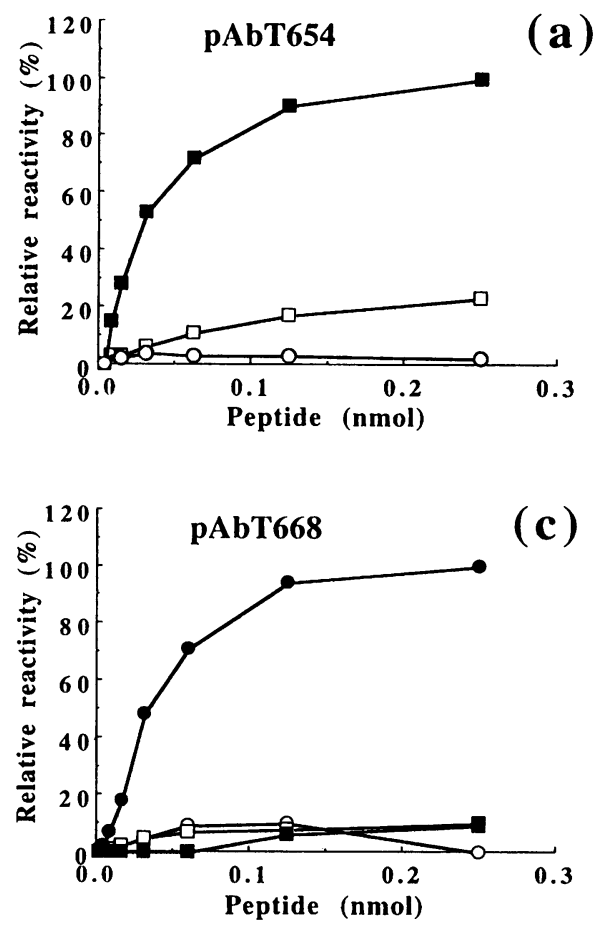
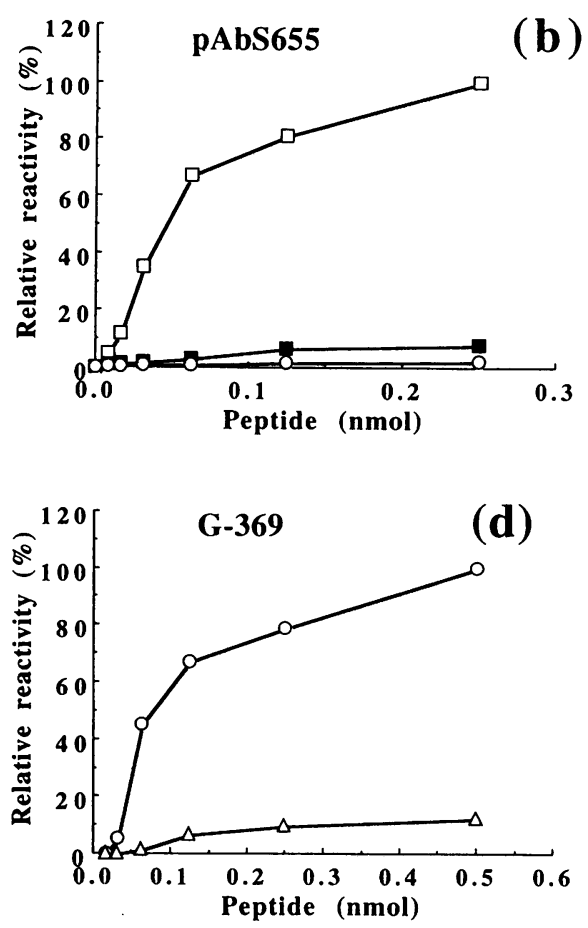

FIG. 2. Specificity of phosphorylation statespecific antibodies towards peptide antigens

The phosphopeptides described in Fig. 1, containing phospho-Thr654 (closed squares), phospho-Ser655 (open squares), phosphoThr668 (closed circles), or dephospho-APP ${ }^{645-694}$ (open circles) and APLP2 ${ }^{717-764}$ (open triangles), were spotted on nitrocellulose filters. Membranes were probed with (a) pAbT654, (b) pAbS655, (c) pAbT668, or (d) G-369 antibodies, followed by $\left[{ }^{125} \mathrm{I}\right]$ protein $\mathrm{A}$, and autoradiography was performed. Radioactivity was quantified with a Molecular Dynamics PhosphorImager. For each antibody, results were calculated as a percentage of the maximal value obtained. of Thr654 and Ser655, APP ${ }^{645-694}$ (6 $\left.\mu \mathrm{g}\right)$ was incubated with purified CaM kinase II $(2 \mu \mathrm{g})$ in a reaction buffer (volume $120 \mu \mathrm{l}$ ) of $50 \mathrm{mM}$ HEPES, pH 7.4, 1 mM EGTA, 2 mM MgCl, $1 \mathrm{mM}$ $\mathrm{CaCl}_{2}, 1 \mathrm{mM}$ ATP, and calmodulin $(20 \mu \mathrm{g} / \mathrm{ml})$ in the presence or absence of $1 \mathrm{mM}$ ATP. For phosphorylation of Ser655, APP ${ }^{645-694}$ was incubated with PKC $(2 \mu \mathrm{g})$ in the above reaction buffer containing phorbol 12,13-dibutyrate (PDBu, $1 \mu \mathrm{M}$ ) instead of calmodulin; for phosphorylation of Thr668, APP ${ }^{645-694}$ was incubated with cdc2 kinase ( $1 \mu \mathrm{g})$, as described previously (18). Reactions were carried out for $3 \mathrm{hr}$. APP ${ }^{645-694}$ was recovered from each reaction mixture by immunoprecipitation with G-369 antibody and protein A-Sepharose (Pharmacia) (17). The stoichiometry of phosphorylation of APP by each kinase was measured in separate parallel reactions in which $\left[\gamma-{ }^{32}\right.$ P]ATP (Dupont-NEN) $(3 \times$ $10^{-5} \mathrm{cpm} / \mathrm{nmol}$ ) replaced unlabeled ATP.

\section{Immunoblot Analysis of APP from Cultured Cells and Rat Brain}

Monolayer cultures of $\mathrm{CHO}$ cells stably transfected with human $\mathrm{APP}_{751}$ (15), PC12 cells, or HeLa cells were lysed as described $(17,18)$, and APP was immunoprecipitated as described
$(17,18)$ with various antibodies as indicated in the figure legends (see Figs. 1-7). Brain tissue from adult Wistar rats (7-10 weeks) was homogenized and sonicated in a solution containing $50 \mathrm{mM}$ Tris- $\mathrm{HCl}(\mathrm{pH} 7.4), 1 \%$ SDS (w/v), $2.7 \mathrm{M}$ urea, $2 \mu \mathrm{M}$ microcystin-LR, $25 \mu \mathrm{g} / \mathrm{ml}$ pepstatin A $(w / v), 25 \mu \mathrm{g} / \mathrm{ml}$ leupeptin (w/v), and $25 \mu \mathrm{g} / \mathrm{ml}$ chymostatin (w/v). Samples were centrifuged $(10,000 \times g, 10 \mathrm{~min})$, and APP was immunoprecipitated using the antibodies indicated in the figure legends (see Figs. 1-7). Proteins were separated by SDS-polyacrylamide gel electrophoresis (SDS-PAGE, 6\% acrylamide) and electrophoretically transferred to nitrocellulose membrane in a buffer $(\mathrm{pH} \mathrm{8.3)}$ containing $25 \mathrm{mM}$ Tris, $192 \mathrm{mM}$ glycine, and $20 \%$ methanol (v/v). Membranes were probed with appropriate antibodies and $\left[{ }^{125} \mathrm{I}\right]$-protein A. Radioactivity was quantitated using a PhosphorImager.

\section{Analysis of APP Phosphorylation in PC12 Cells and HeLa Cells}

PC12 cells $\left(2-3 \times 10^{6}\right)$ were cultured in Dulbeco's modified Eagles's medium (DMEM) containing $10 \%$ heat-inactivated fetal calf serum (FCS) 


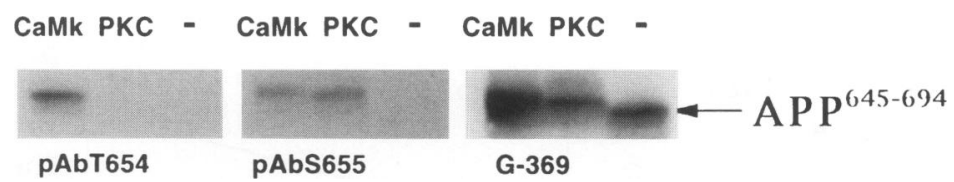

FIG. 3. Specificity of phosphorylation state-specific antibodies towards enzymatically phosphorylated APP ${ }^{645-694}$

$\mathrm{APP}^{645-694}$ (6 $\mu \mathrm{g}$ ) was incubated with nonradioactive ATP and CaM kinase II (CaMk), PKC, or without enzymes $(-)$. Samples were subjected to SDS-PAGE, and transferred to nitrocellulose membranes. Membranes were probed with pAbT654 (lanes 1 to 3), pAbS655 (lanes 4 to 6), or G-369 (lanes 7 to 9) antibodies, followed by [ ${ }^{125}$ I]-protein $\mathrm{A}$, and autoradiography was performed. The arrow indicates the position of dephospho-APP ${ }^{645-694}$.

$(\mathrm{v} / \mathrm{v})$ and $5 \%$ heat-inactivated horse serum $(v / v)$. Cells were incubated in medium containing either dimethyl sulfoxide (DMSO) (control experiments), PDBu (1 $\mu \mathrm{M}$ in DMSO), okadaic acid ( $2 \mu \mathrm{M}$ in DMSO), or $1 \mu \mathrm{M}$ PDBu plus $2 \mu \mathrm{M}$ okadaic acid for $1 \mathrm{hr}$ at $37^{\circ} \mathrm{C}$. HeLa cells $(2-3 \times$ $10^{6}$ ) were grown in DMEM containing $10 \%$ heat-inactivated FCS (v/v) (complete DMEM). Cells were subjected to serum starvation in DMEM containing $0.5 \%$ FCS (limited DMEM) for $24 \mathrm{hr}$. Gl phase cells were further cultured in fresh limited DMEM for 12 hr. For S-phase synchronization, cells were further cultured in complete DMEM containing either aphidicolin $(5 \mu \mathrm{g} /$ $\mathrm{ml})$ or hydroxyurea $(5 \mu \mathrm{g} / \mathrm{ml})$ for $12 \mathrm{hr}$. For G2/M-phase synchronization, cells were further cultured in complete DMEM containing nocodazole $(1 \mu \mathrm{g} / \mathrm{ml}$ ) for $12 \mathrm{hr}$. The cells were then lysed and APP was immunoprecipitated with primary antibody as indicated. Cells treated in parallel were also analyzed on a Becton Dickinson FACScan Flow Cytometer to determine their state of synchronization as described previously (18).

\section{RESULTS}

\section{Preparation of Phosphorylation State-Specific Antibodies}

Our previous studies of several phosphorylation systems have revealed the usefulness of phosphorylation state-specific antibodies to study the in situ phosphorylation of various substrates $(22,23,27,28)$. To address the question of phosphorylation of APP in intact cells and in brain, synthetic phosphopeptide antigens (Fig. 1) were synthesized and antibodies raised that recognized specifically APP phosphorylated at either phospho-Thr654 (pAbT654), phospho-Ser655 (pAbS655), or phospho-Thr668 (pAbT668).
Each antibody reacted with its corresponding phosphorylated peptide antigen, but not with unphosphorylated APP ${ }^{645-694}$ (Fig. 2). A low degree of cross-reactivity ( 15\%) was observed for pAbT654 with the peptide containing phosphoSer655. Little or no cross-reactivity was observed for pAbS655 or pAbT668 with the other phosphorylated peptides tested.

To further characterize the phosphorylation state-specific antibodies, APP ${ }^{\text {645-694 }}$ was phosphorylated with either CaM kinase II (which phosphorylates Thr654 and Ser655 to a similar level) or PKC (which phosphorylates Ser655) in parallel reactions either with nonradioactive ATP or $\left[\gamma^{32} \mathrm{P}\right]$ ATP. Samples of reaction mixtures using nonradioactive ATP were immunoprecipitated with G-369, subjected to electrophoresis, and transferred onto nitrocellulose membrane, then probed with either pAbT654, pAbS655, pAbT668, or G-369 antibodies (Fig. 3). pAbT654 recognized APP ${ }^{645-694}$ phosphorylated by CaM kinase II, but not PKC. The antibody pAbS655 recognized samples of APP ${ }^{645-694}$ that had been phosphorylated by either CaM kinase II or PKC. pAbT668 did not exhibit detectable cross-reactivity towards APP ${ }^{645-694}$ that had been phosphorylated by either CaM kinase II or PKC (data not shown). None of the three phospho-specific antibodies displayed cross-reactivity to dephospho-

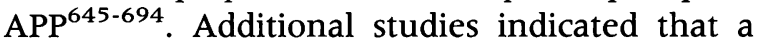
linear relationship existed between immunoreactivity measured for each antibody and that measured by ${ }^{32} \mathrm{P}$ incorporation (data not shown). The amount of APP ${ }^{645-694}$ recovered following immunoprecipitation with G-369 was very similar irrespective of the kinase used (Fig. 3 and data not shown). Furthermore, the reactivity of G-369 towards APP ${ }^{645-694}$ phosphorylated at any site was identical to that towards dephosphoAPP 645-694 (Fig. 3 and data not shown). Thus, phosphorylation of any site in $\mathrm{APP}^{645-694}$ does 
not appear to affect its interaction with the G-369 antibody.

\section{Phosphorylation of APP at Thr654, Ser655, and Thr668 in Cultured Cell Lines}

Previous studies have shown that Thr668 of APP is phosphorylated by cdc2 kinase in a cell cycledependent manner at the G2/M phase of the cell cycle (18). To validate the specificity of the pAbT668 antibody and to provide a quantitative measure of the level of phosphorylation of Thr668 at all stages of the cell cycle, HeLa cells at different stages of the cell cycle were prepared. The stage of the cell cycle was determined using fluoresence-activated cell sorting (FACS) analysis (Fig. 4a, lower panel). APP was immunoprecipitated from cell lysates obtained from Gl phase, $S$ phase (synchronized with aphidicolin or hydroxyurea), and G2/M phase (synchronized with nocodazole) (Fig. 4a and b). The phosphorylation of APP at Thr668 measured using pAbT668 changed dramatically: very high levels were found at the G2/M phase, low levels at the Gl phase, and essentially no phosphorylation was found during $S$ phase (Fig. 4a and b). As described previously, two immature imAPP $_{751}$ and imAPP $\left.{ }_{770}\right)$ and two mature $\left(\mathrm{mAPP}_{751}\right.$ and $\mathrm{MAPP}_{770}$ ) APP isoforms were detected in HeLa cells (18). The total content of immature or mature APP isoforms measured by immunoblot analysis with the G-369 antibody did not change significantly at any point in the cell cycle (Fig. 4a and b). However, a qualitative change was observed in the migration of $\operatorname{imAPP}_{751}$ and imAPP $_{770}$ on SDS-PAGE. In G2/M phase cells, the imAPP isoforms appeared as a doublet that exhibited reduced mobility (Fig. 4a). Furthermore, the phosphorylated forms of APP detected with pAbT668 comigrated with the two immature isoforms showing reduced electrophoretic mobility.

The phosphorylation of APP at Thr654 and Ser655 was studied in PC12 and CHO cells. PC12 cells express three immature and three mature isoforms of APP (imAPP $695, \mathrm{imAPP}_{751}, \mathrm{imAPP}_{770}$, $\mathrm{mAPP}_{695}, \mathrm{mAPP}_{751}, \mathrm{mAPP}_{770}$ ), which were detected with G-369 antibody (Fig. 5). Using the pAbT654 and pAbS655 antibodies, imAPP ${ }_{751}$ and $\operatorname{imAPP}_{770}$, and to a lesser degree, $\mathrm{mAPP}_{751}$ and $\mathrm{mAPP}_{770}$, were found to be phosphorylated at both Thr654 and Ser655. In CHO cells stably transfected with human $\mathrm{APP}_{751}$ (Fig. 5b), phosphorylation of $\operatorname{imAPP}_{751}$ at Thr654 and Ser655 was also detected with the pAbT654 and pAbS655 antibodies.

To further characterize the phosphorylation of APP at Thr654 and Ser655, PCl2 cells were treated with agents that regulate protein phosphorylation and dephosphorylation, and the relative levels of APP and phospho-APP were measured. In vitro and in semi-intact cells, PKC has been found to phosphorylate Ser655 $(16,17)$, and in vitro, phosphoprotein phosphatase $2 \mathrm{~A}$ has been found to dephosphorylate APP phosphorylated at all three sites (Kwon et al., unpublished results). Therefore, cells were treated either with $\mathrm{PDBu}$ to activate $\mathrm{PKC}$, or with okadaic acid to inhibit phosphatase $2 \mathrm{~A}$, or with a combination of both PDBu and okadaic acid (Fig. 6a). Treatment of cells with PDBu failed to increase phosphorylation at Ser655; treatment with okadaic acid increased (more than 10-fold) phosphorylation at Ser655 in mature, but not immature, isoforms of APP. Notably, the treatment with a combination of PDBu and okadaic acid resulted in a level of phosphorylation at Ser655 that was similar to untreated controls, i.e., PDBu was able to prevent the phosphorylation seen with okadaic acid alone.

As previously reported, the amount of mAPP detected in cells was decreased by treatment with either PDBu or okadaic acid (21). In the present study, PDBu treatment decreased the level of mAPP by $40 \%$, okadaic acid decreased the level by $60 \%$, and the combination of PDBu and okadaic acid decreased the level by $70 \%$ (Fig. 6a and b). After adjusting for the decrease in total mature APP, the level of phosphorylation at Ser655 caused by treatment of cells with okadaic acid was more than 25 -fold greater than control.

The phosphorylation of Thr654 was not affected by treatment with PDBu or okadaic acid (data not shown). Furthermore, treatment of PC12 cells with the calcium ionophore A23187 had no effect on the phosphorylation of Thr654 or Ser655.

\section{Phosphorylation of APP in Brain}

To identify APP isoforms in adult rat brain, APP was immunoprecipitated with G-369 antibody and samples were immunoblotted with either G-369 antibody or an antibody that recognizes the KPI domain present only in the two longer isoforms of the protein (Fig. 7a). Three major bands and two minor bands were detected with the G-369 antibody and one major band and one minor band were detected with the anti-KPI an- 
(a)

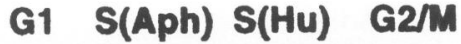

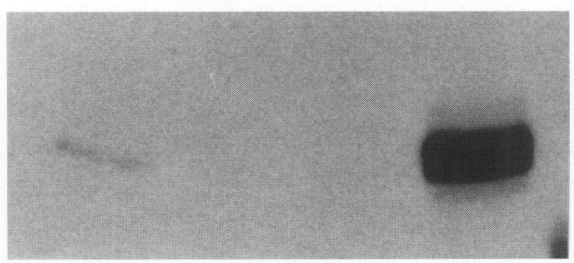

pAbT668
G1 S(Aph) S(Hu) G2/M

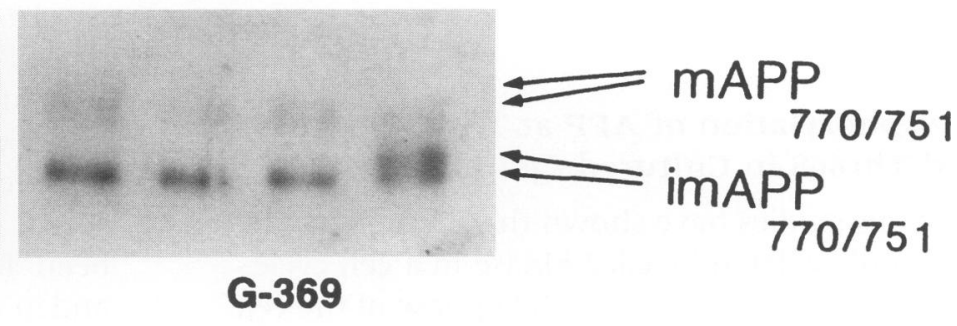

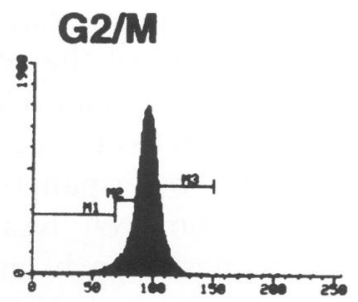

(b)
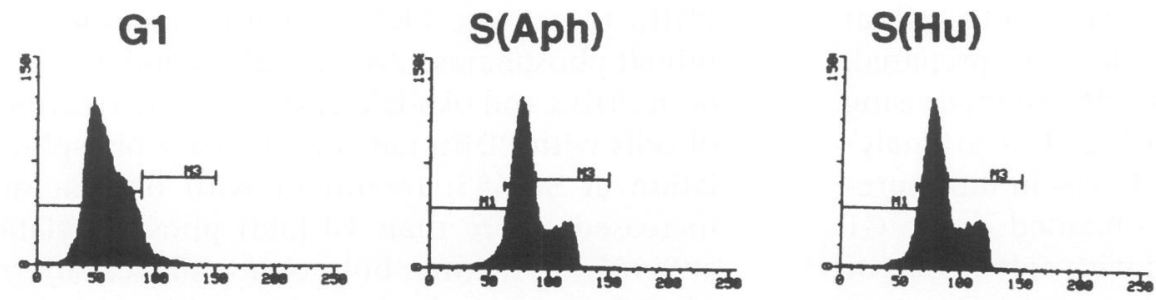

Phosphorylation Level

Amount of imAPP

of imAPP at Thr 668
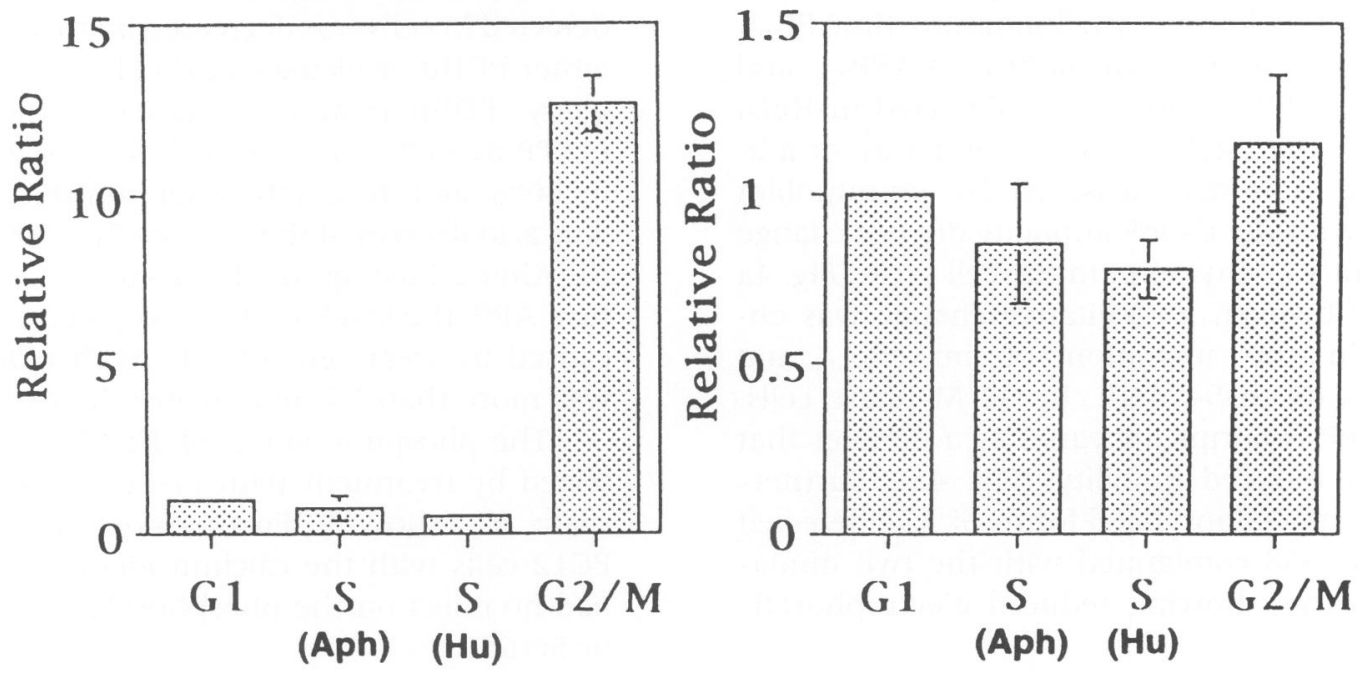

Cell Cycle Stage

FIG. 4. Cell cycle-dependent phosphorylation of Thr668 of APP

HeLa cells were synchronized at various cell cycle stages: Gl (synchronized by serum withdrawal and re-addition), $\mathrm{S}$ (synchronized with aphidicolin [Aph]), S (synchronized with hydroxyurea [Hu]), and G2/M (synchronized with nocodazole). APP was immunoprecipitated from cell extracts with G-369 antibody, samples were subjected to SDS-PAGE (6\% acrylamide gel) and transferred to nitrocellulose membranes. (a) Upper panel: immunoblots were probed with pAbT668 or G-369 antibodies, [ $\left.{ }^{125} \mathrm{I}\right]$-protein A, and autoradiography performed. (b) Lower panel: cell cycle stages were determined by FACS scan analysis. Immunoblots shown in (a) were analyzed with a Molecular Dynamics PhosphorImager, and the relative levels of phosphorylated APP and total immature APP 770/751 calculated for each cell-cycle stage. Values for the Gl samples were set at unity. The data shown are the averages of two independent studies. 
(a) PC12 Cells

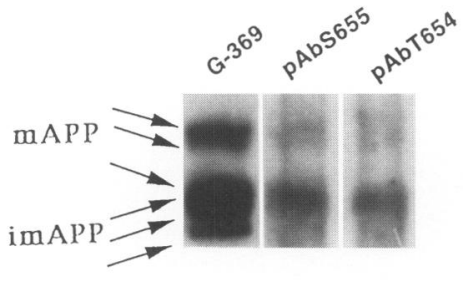

(b) CHO Cells

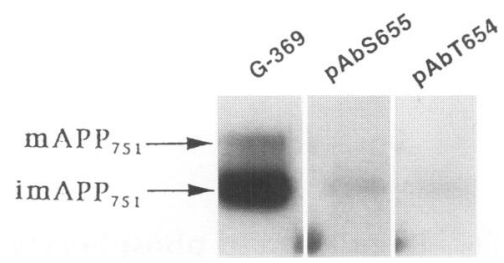

FIG. 5. Phosphorylation of Thr654 and Ser655 of APP in cultured cell lines

APP was immunoprecipitated from (a) PC12, or (b) CHO cell lysates using the G-369 antibody. Samples were subjected to SDS-PAGE and immunoblotting as described above. Membrane strips were probed with either G-369, pAbS655, or pAbT654 antibodies. (a) The arrows indicate the positions of the three immature and three mature APP isoforms found in PC 12 cells (see text for discussion). In the experiment shown, lanes 2 and 3 were exposed five times longer than lane l. (b) CHO cells were stably transfected with a cDNA construct encoding $\mathrm{APP}_{751}$. The arrows indicate the positions of immature and mature isoforms of $\mathrm{APP}_{751}$. For all conditions studied, immunoreactivity detected by phosphorylation state-specific antibodies in all cell lines was competed away when each antibody was preincubated with the corresponding phospho-peptide antigen $(10 \mu \mathrm{M})$ (data not shown).

tibody. Based on these and previous studies (29), we have tentatively identified the different bands as follows: band 1 is $\mathrm{mAPP}_{770}$, band 2 is $\mathrm{mAPP}_{751}$, band 3 is a mixture of $\mathrm{mAPP}_{695}$ and imAPP ${ }_{770}$, band 4 is imAPP 751 , and band 5 is imAPP 695 .

APP from rat brain was immunoprecipitated with either the pAbT654 or pAbS655 antibodies, then probed with the G-369 antibody (Fig. 7a). In both cases, $\mathrm{mAPP}_{770}$ and $\mathrm{mAPP}_{751}$ isoforms were found to be phosphorylated. Following immunoprecipitation with the G-369 antibody and immunoblotting with the pAbT668 antibody, $\mathrm{mAPP}_{695}$ and/or imAPP 770 , and imAPP 751 isoforms were found to be phosphorylated. There were no significant differences in the levels of phosphorylation of Thr668 sites in different brain regions (cortex, hippocampus, and substantia nigra were analyzed, data not shown). No apparent phosphorylation of imAPP ${ }_{695}$ was detected with any of the phospho-specific antibodies.

To confirm the identification of the rat brain APP isoforms and the phosphorylation of Thr668, several additional studies were performed. No immunoreactivity was detected when the pAbT668 antibody was preabsorbed with its phosphorylated antigen peptide before the immunoblot analysis (Fig. 7b). Similar results were obtained when the pAbT654 or pAbS655 antibodies were preincubated with their corresponding peptide antigens (data not shown). Furthermore, APP was immunoprecipitated with either the G-369 or pAbT668 antibodies and the immunoprecipitates were incubated with bacterial alkaline phosphatase (Fig. 7c). No immunoreactivity was detected with the pAbT668 antibody following treatment of APP with alkaline phosphatase. Similar results were observed for APP isoforms detected with the pAbT654 and pAbS655 antibodies (data not shown). Treatment of APP (immunoprecipitated with pAbT668) with alkaline phosphatase did not affect its ability to be detected by immunoblotting with the G-369 antibody. This result indicated that total APP content was not affected by incubation with the phosphatase.

Recently, several amyloid precursor-like proteins (APLP) have been identified, including APLP2, which has an amino acid sequence that is very similar to APP (30). In particular, the cytoplasmic domains of APP and APLP2 are highly conserved and APLP2 contains a potential phosphorylation site homologous to Thr668 of APP. However, APLP2 does not contain the A $\beta$ domain. Therefore, studies were performed in which APP was immunoprecipitated with an antibody, G-530, that specifically recognizes rat $\mathrm{A} \beta^{1-16}$. Following immunoprecipitation of rat brain APP with either the G-369 or G-530 antibodies, the three major (Fig. 7d) and two minor isoforms (data not shown) of APP were detected following immunoblotting with G-369. In addition, pAbT668 immunoreactivity, as measured by immunoblotting, was identical towards APP immunoprecipitated by either antibody.

\section{DISCUSSION}

Previous studies had indicated that three sites in the cytoplasmic domain of APP, Thr654, Ser655, and Thr668, were phosphorylated in vitro, respectively, by CaM kinase II, PKC, and cdc2 ki- 
(a)

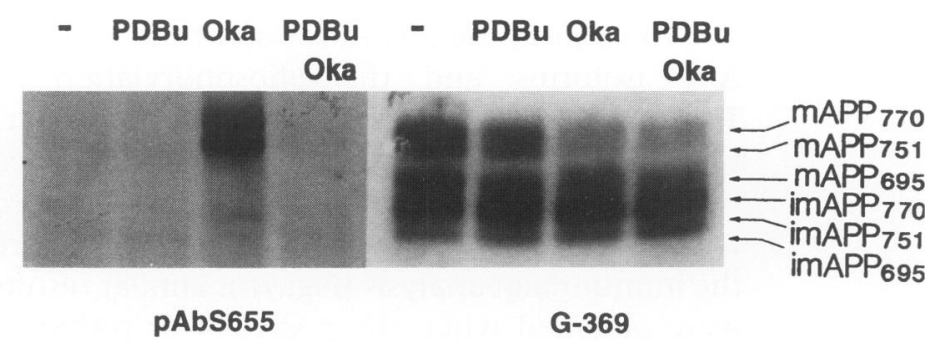

(b)

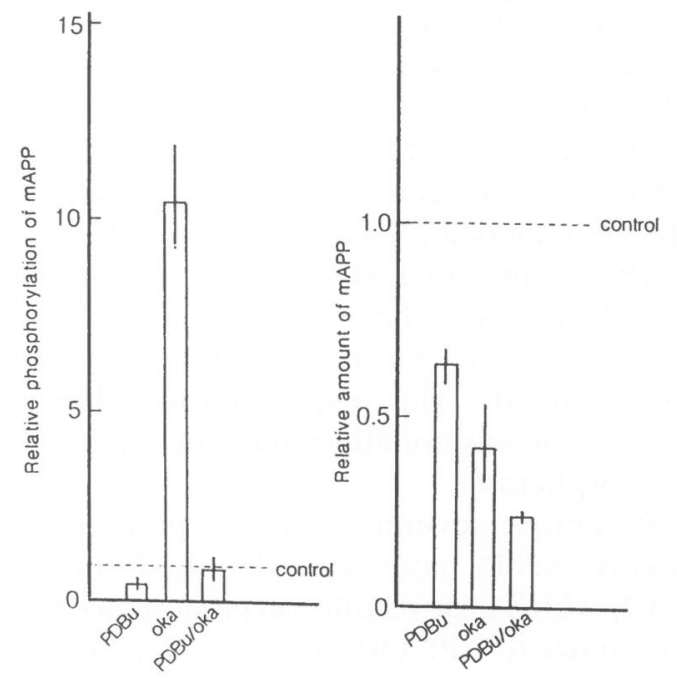

FIG. 6. Regulation of phosphorylation of Ser655 of APP in PC12 cells

PC1 2 cells were treated with phorbol ester (PDBu), okadaic acid (Oka), a combination of PDBu and okadaic acid (PDBu/Oka), or without any addition (-) for $1 \mathrm{hr}$. APP was recovered by immunoprecipitation with G-369 antibody, and samples were subjected to SDSPAGE and immunoblotting as described. (a) Membrane strips were probed with either the pAbS655 (left) or G-369 (right) antibodies. The arrows indicate the positions of mature and immature APP isoforms. (b) The levels of phosphorylation of Ser655 in MAPP $_{770 / 751}$ (left) and the total amount of $\mathrm{MAPP}_{770 / 751}$ (right) were determined by using a Molecular Dynamics PhosphorImager. In each case, the results were normalized to the values obtained without any addition. The data shown are the averages of two independent studies.

nase (16-18). However, only Thr668 had been demonstrated to be phosphorylated in intact cells (18). Difficulties in detecting phosphorylation at Thr654 or Ser655 in cultured cells raised the possibility that phosphorylation of these sites may not be physiologically important, that the appropriate conditions to stimulate relevant protein kinases had not been determined, and/or that the rate of dephosphorylation of phosphoThr654 or phospho-Ser655 may be high. In the present study, we have prepared antibodies specific for the phosphorylated forms of each of the three sites in APP and used these to show that Thr654, Ser655, and Thr668 are phosphorylated both in cultured cells and in adult rat brain. Therefore, the results obtained from in vitro and in vivo studies together indicate that phosphorylation of Thr654, Ser655, and Thr668 is likely to be of physiological relevance, and that the phos- phorylation of APP at these sites may play some role in the biological function(s) of the protein.

Our previous studies showed that antibodies can be prepared that recognize the phosphorylated form of a protein within the context of specific phosphorylation sites $(22,23,27,28)$. In addition to the phosphorylated amino acid, such antibodies appear to recognize other specific amino acid residues surrounding the phosphorylation site. The results obtained in the present study further highlight the powerful nature of this technique for use in the analysis of the phosphorylation of substrate proteins in situ. Notably, the pAbT654 and pAbS655 antibodies are able to distinguish the phosphorylation of adjacent amino acids. This result, as well as similar results obtained recently for phospholamban (31), highlight the remarkable degree of specificity that can 
(a)

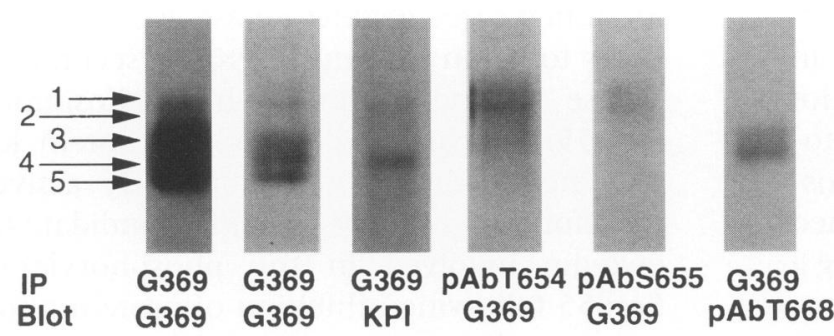

(b)

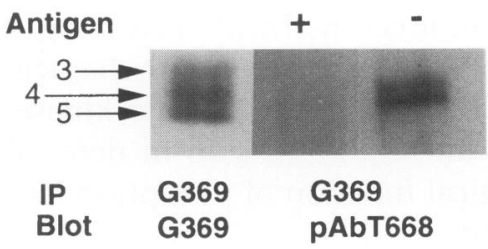

(c)

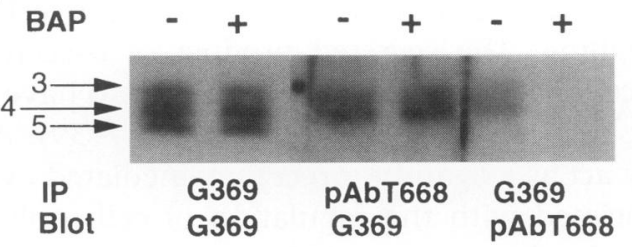

(d)

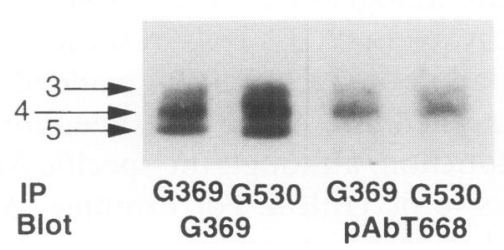

be achieved with phosphorylation state-specific antibodies.

The results clearly indicate that different isoforms of APP are phosphorylated. Moreover, the antibodies do not appear to cross-react with APPrelated proteins such as APLP2. The results do not, however, exclude the possibility that APLP2 may also be phosphorylated in intact cells at one or more sites. Indeed, it has recently been demonstrated that the cytoplasmic domain of APLP2 is phosphorylated by several different protein kinases in vitro, including cdc2 kinase, and in intact cells (T. Suzuki et al, unpublished data). However, pAbT668 does not recognize APLP2 ${ }^{717-764}$ phosphorylated at Thr 736 by cdc 2 kinase, presumably because the $\mathrm{NH}_{2}$-terminal residues adjacent to the site phosphorylated in APP (Thr668 in the sequence AAVT(P)PEER) are not conserved in APLP2 (Thr736 in the sequence PMLT (P)PEER).
FIG. 7. Phosphorylation of APP in adult rat brain

(a) APP was immunoprecipitated from adult rat brain lysates ( $5 \mathrm{mg}$ total protein) using G-369, pAbT654, or pAbS655 antibodies, as indicated. Samples were subjected to SDS-PAGE and immunoblotting as described above. Membrane strips were probed with either G-369, anti-KPI domain $(56,1)$ or pAbT688 antibodies, as indicated. The arrows indicate the positions of mature and immature APP isoforms (see text). Lanes 1 and 2 represent different exposures of the same sample probed with G-369 antibody. (b) and (c) APP was immunoprecipitated from adult rat brain (7 $\mathrm{mg}$ total protein) using either G-369 or pAbT688 antibodies as indicated. Samples were subjected to SDS-PAGE and immunoblotting as described above. Membrane strips were probed with either G-369 or pAbT688 antibodies as indicated. Antigen +: Prior to immunoblotting, pAbT688 antibody was preincubated with $\mathrm{APP}_{695}[665-673] \mathrm{P}-\mathrm{Thr}^{668}{ }^{6} \mathrm{Cys}^{673}(10 \mu \mathrm{M})$. In some cases prior to immunoblotting, immunoprecipitates were incubated with bacterial alkaline phosphatase (40 unit) (BAP+) or without any addition (BAP-) in a buffer containing 0.5 $M$ Tris- $\mathrm{HCl}(\mathrm{pH} 7.9), 12.5 \mathrm{mM} \mathrm{MgCl} 2,8.3 \%$ (v/v) glycerol, $200 \mu \mathrm{g} / \mathrm{ml}(\mathrm{w} / \mathrm{v})$ pepstatin A, 200 $\mu \mathrm{g} / \mathrm{ml}(\mathrm{w} / \mathrm{v})$ leupeptin, and $200 \mu \mathrm{g} / \mathrm{ml}(\mathrm{w} / \mathrm{v})$ chymostatin. The arrows indicate the positions of immature isoforms of APP. (d) APP was immunoprecipitated from adult rat brain $(5 \mathrm{mg}$ total protein) with G-369 or G-530 (anti-rat $\left.A \beta_{1-16}\right)$ antibodies as indicated. Samples were subjected to SDS-PAGE and immunoblotting as described above. Membranes were probed with G-369 or pAbT668 antibodies as indicated. The arrows indicate immature APP isoforms.

The pAbT668 antibody was used to demonstrate that Thr668 in APP was phosphorylated in cultured cells in a cell cycle-dependent manner with the highest level of phosphorylation being found at the G2/M phase of the cell cycle. These results are consistent with our previous data, although only a 2 - to 3 -fold increase in phosphorylation was observed with ${ }^{32} \mathrm{P}$-prelabeling methods (18). The results in the present study demonstrate the greater sensitivity of the phospho-specific antibodies for measurement of phosphorylation of proteins in vivo. The greater specificity of the pT668 antibody helped to demonstrate that only immature isoforms of APP were phosphorylated by cdc2 kinase at the G2/M phase of the cell cycle. The results also demonstrate that Thr668 is phosphorylated in adult rat brain. As observed for cultured cells, immature isoforms of APP appeared to be phosphorylated predominantly in brain, although immature 
$\mathrm{APP}_{695}$, a neuron-specific isoform (4), was not. This observation raises the possibility that APP is phosphorylated by cdc2 kinase at Thr668 only in glial cells, which are capable of division, but not in neurons. However, recent immunohistochemical studies suggest that Thr668 is phosphorylated in neurons (Satoh et al., unpublished data), which do not express cdc2 kinase, raising a question as to the identity of the kinase responsible. One candidate is cdk5, the catalytic subunit of which is is expressed at high levels in brain (for review, see ref. 32). Furthermore, a noncyclin activator of cdk5, p35, is specifically expressed in neurons (32). An alternative possibility for phosphorylation of Thr668 is glycogen synthase kinase-3, a kinase that is abundant in neurons (33), and is known to phosphorylate Ser-Pro and Thr-Pro sites that are present in paired helical filament tau (34-36).

The level of phosphorylation of Thr654 and Ser655 in rat brain was found to be relatively low; however, treatment of PC12 cells with okadaic acid significantly increased the phosphorylation of Ser655, suggesting that mechanisms exist, at least in the case of Ser655, that can increase the stoichiometry of phosphorylation. A complicating factor in the analysis of mature APP isoforms following treatment of cells with phorbol ester or okadaic acid is that these reagents also affect the processing of APP by regulation of $\alpha$-secretase cleavage $(14,21)$. In addition, the levels of mature isoforms of APP are low in adult brain. It is also possible that phosphorylation of the cytoplasmic domain accompanies $\alpha$-secretase cleavage, making it difficult to detect phosphorylation of intact mature isoforms of APP. It will be interesting to study whether the levels of phosphorylation at any these sites is altered in the $\mathrm{AD}$ brain.

Previous studies have shown that Ser655 is phosphorylated by PKC in vitro and in semiintact cells $(16,17)$. However, in the present study, treatment of PC12 cells with PDBu, an activator of $\mathrm{PKC}$, failed to increase the phosphorylation of Ser655. Furthermore, in ${ }^{32} \mathrm{P}$-prelabeling studies, phosphorylation of APP at Ser655 was not observed in PC 12 cells after treatment with phorbol ester (T. Suzuki, unpublished results). Therefore, PKC isotypes responsive to $\mathrm{PDBu}$ are not likely to be responsible for the phosphorylation of the cytoplasmic domain of APP, at least in PC12 cells. Recently, we have analyzed the protein kinase activities that phosphorylate the cytoplasmic domain of APP in extracts prepared from rat brain or PC12 cells (T.
Isohara et al., unpublished results). We have identified three distinct kinase activities: one appears to be an isoform of PKC, a second is CaM kinase II, and a third, which phosphorylates Ser655, appears to be a novel protein kinase. This novel kinase is constitutively active and therefore represents a potential candidate for the enzyme involved in the phosphorylation of Ser655 following inhibition of protein phosphatase $2 \mathrm{~A}$. Alternatively, the ability of okadaic acid to stimulate phosphorylation of Ser655 may be through an indirect pathway involving other protein kinase(s). Purification and characterization of the novel Ser655 protein kinase will hopefully be an important step in determining the physiological function of phosphorylation of Ser655 of APP.

The structure, cellular distribution, and metabolism of APP suggest that the protein may play a role in one or more aspects of cellular signalling. The secreted product of $\alpha$-secretase processing, $\mathrm{APP}_{\mathrm{S}}$, has been observed to have trophic activity on several cell types (37-39). $\mathrm{APP}_{\mathrm{S}}$ may act as a ligand for receptor-mediated events associated with the regulation of cell proliferation. In this respect, $\mathrm{APP}_{\mathrm{S}}$ has been shown to stimulate the mitogen-associated protein (MAP) kinase pathway in $\mathrm{PC} 12$ cells resulting in the phosphorylation of tau (40). When added to the extracellular medium, $A \beta$ has also been found to affect cell function, although the specific $A \beta$ species appears to be critical. For example, $A \boldsymbol{\beta}$ has been found to increase intracellular $\mathrm{Ca}^{2+}$ levels and to be neurotoxic $(41,42)$, to affect $\mathrm{K}^{+}$channel function (43), and to activate serine/threonine protein kinase activity (44). Alternatively, the extracellular domain of APP may act as a receptor for an unidentified ligand. In this case, the conserved cytoplasmic domain of each APP isoform would be expected to interact with other proteins in the cell that are themselves involved in signal transduction. Clearly, identification of proteins that interact with the intracellular domain of APP will be important in clarifying the role(s) of APP in signal transduction. Since the short intracellular domain of APP appears to have no enzymatic activity, the phosphorylation of the intracellular $\mathrm{COOH}$-terminal domain in APP is likely to regulate the interaction of the domain with one or more binding proteins. The identification of the proteins that associate with the APP cytoplasmic domain and the characterization of the mechanisms that regulate their interaction with APP, including the possible role of phosphorylation of Thr654, Ser655, and 
Thr668, should contribute to our understanding of the physiological and pathological metabolism of APP.

\section{ACKNOWLEDGMENTS}

We thank Dr. J. D. Buxbaum, Dr. E. H. Koo, and Dr. Y. Kirino for helpful discussion. This research was supported by US PHS grant AG09464 (A.C.N., S.G., A.J.C. P.G.), AG10491 (P.G.), and AG1 1508 (S.G.), and by The Mochida Memorial Foundation For Medical and Pharmaceutical Research (T.S.), The Naito Foundation (T.S.), The Life Science Foundation (T.S.), The Foundation of Pharmaceutical Research (T.S.), and a grantin-aid for scientific research from The Japanese Ministry of Education, Science, Sports and Culture (No. 07457536) (T.S.).

\section{REFERENCES}

1. Glenner G, Wong C. (1984) Alzheimer's disease: Initial report of the purification and characterization of a novel cerebrovascular amyloid protein. Biochem. Biophys. Res. Commun. 122: 885-890.

2. Masters CL, Simms G, Weinmann NA, Multhaup G, McDonald BL, Beyreuther $\mathrm{K}$. (1985) Amyloid plaque core protein in Alzheimer disease and Down syndrome. Proc. Natl. Acad. Sci. U.S.A. 82: 4245-4249.

3. Goldgaber D, Lerman MI, McBride OW, Saffiotti U, Gajdusek DC. (1987) Characterization and chromosomal localization of a cDNA encoding brain amyloid of Alzheimer's disease. Science 235: 877-880.

4. Kang J, Lemaire HG, Unterbeck AJ, Salbaum JM, Master CL, Grzeschik KH, Multhaup G, Beyreuther K, Muller-Hill B. (1987) The precursor of Alzheimer's disease amyloid A4 protein resembles a cell-surface receptor. $\mathrm{Na}$ ture 325: 733-736.

5. Robakis NK, Ramakrishna N, Wolfe G, Wisniewski HM. (1987) Molecular cloning and characterization of a cDNA encoding the cerebrovascular and the neuritic plaque amyloid peptide. Proc. Natl. Acad. Sci. U.S.A. 84: 4190-4194.

6. Tanzi RE, Gusella JF, Watkins PC, Brus GAP, St George-Hyslop P, Van Keuren ML, Patterson D, Pagan S, Kurnit DM, Neve RL. (1987) Amyloid $\beta$ protein gene: mRNA distribution and genetic linkage near the Alzheimer's locus. Science 235: 880-884.

7. Tanzi RE, McClatchey AI, Lamperti ED, Komaroff LV, Gusella JF, Neve RL. (1988) Protease inhibitor domain encoded by an amyloid protein precursor mRNA associated with Alzheimer's disease. Nature 331: 528530.

8. Ponte P, Gonzales-De Whitt P, Schilling J, Miller J, Hsu D, Greenberg B, Davis K, Wallace W, Lieberburg I, Fuller F, Cordell B. (1988) A new A4 amyloid mRNA contains a domain homologous to serine protease inhibitors. Nature 331: 525-527.

9. Kitaguchi N, Takahashi Y, Tokushima Y, Shiojiri S, Ito H. (1988) Novel precursor of Alzheimer's disease amyloid protein shows protease inhibitory activity. Nature 331: 530-532.

10. De Sauvage F, Octave J-N. (1989) A novel mRNA of the A4 amyloid precursor gene coding for a possibly secreted protein. Science 245: 651-653.

11. Weidemann A, Konig G, Bunke D, Fischer P, Salbaum JM, Master CL, Beyreuther K. (1989) Identification, biogenesis and localization of precursors of Alzheimer's disease A4 amyloid protein. Cell 57: 115-126.

12. Saitoh T, Masliah E, Jin L-W, Cole GM, Wieloch T, Shapiro IP. (1991) Biology of disease: Protein kinase and phosphorylation in neurologic disorders and cell death. Lab. Invest. 64: 596-616.

13. Gandy SE, Caporaso GL, Ramabhadran TV, Suzuki T, Buxbaum JD, Nordstedt C, Iverfeldt K, Czernik AJ, Nairn AC, Greengard P. (1992) Characterization of alternative routes for processing of the Alzheimer $\beta / \mathrm{A} 4$-amyloid precursor protein. Differential effects of phorbol esters and chloroquine. Ann. N. Y. Acad. Sci. 674: 203-217.

14. Caporaso GL, Gandy SE, Buxbaum JD, Ramabhadran TV, Greengard P. (1992) Protein phosphorylation regulates secretion of Alzheimer $\beta / A 4$-amyloid precursor protein. Proc. Natl. Acad. Sci. U.S.A. 89: 3055-3059.

15. Buxbaum JD, Koo ED, Greengard P. (1993) Protein phosphorylation inhibits production of Alzheimer amyloid $\beta /$ A4 peptide. Proc. Natl. Acad. Sci. U.S.A. 90: 9195-9198.

16. Gandy SE, Czernik AJ, Greengard P. (1988) Phosphorylation of Alzheimer disease amyloid precursor peptide by protein kinase $C$ and $\mathrm{Ca}^{2+}$ /calmodulin-dependent kinase II. Proc. Natl. Acad. Sci. U.S.A. 85: 6218-6221. 
17. Suzuki T, Nairn AC, Gandy SE, Greengard P. (1992) Phosphorylation of Alzheimer amyloid precursor protein by protein kinase C. Neuroscience 48: 755-761.

18. Suzuki T, Oishi M, Marshak DR, Czernik AJ, Nairn AC, Greengard P. (1994) Cell cycledependent regulation of the phosphorylation and metabolism of the Alzheimer amyloid precursor protein. $E M B O$ J. 13: 11141122.

19. Knops J, Gandy S, Greengard P, Lieberburg I, Sinha S. (1993) Serine phosphorylation of the secreted extracellular domain of APP. Biochem. Biophys. Res. Commun. 197: 380385.

20. Hung AY, Selkoe DJ. (1994) Selective ectodomain phosphorylation and regulated cleavage of $\beta$-amyloid precursor protein. EMBO J. 13: 534-542.

21. Buxbaum JD, Gandy SE, Cicchetti P, Ehrlich ME, Czernik AJ, Fracasso RP, Ramabhadran TV, Unterbeck AJ, Greengard P. (1990) Processing of Alzheimer $\beta / \mathrm{A} 4$ amyloid precursor protein: Modulation by agents that regulate protein phosphorylation. Proc. Natl. Acad. Sci. U.S.A. 87: 6003-6006.

22. Czernik AJ, Girault J-A, Nairn AC, Chen J, Snyder G, Kebabian J, Greengard P. (1991) Production of phosphorylation state-specific antibodies. Methods Enzymol. 201: 264-283.

23. Czernik AJ, Mathers J, Tso K, Greengard P, Mische SM. (1995) Phosphorylation statespecific antibodies: Preparation and applications. Neuroprotocols 6: 56-61.

24. Wunderlich D, Lee A, Fracasso RP, Mierz DV, Bayney RM, Ramabhadran TV. (1992) Use of recombinant fusion proteins for generation and rapid characterization of monoclonal antibodies. Application to the Kunitz domain of human beta amyloid precursor protein. J. Immunol. Methods 147: 1-11.

25. Lai Y, Nairn AC, Greengard P. (1986) Autophosphorylation reversibly regulates the $\mathrm{Ca}^{2+} /$ calmodulin-dependence of $\mathrm{Ca}^{2+} / \mathrm{cal}-$ modulin-dependent protein kinase II. Proc. Natl. Acad. Sci. U.S.A. 83: 4253-4257.

26. Woodgett JR, Hunter T. (1987) Isolation and characterization of two distinct forms of protein kinase C. J. Biol. Chem. 262: 4836-4843.

27. Nairn AC, Detre JA, Casnellie JE, Greengard P. (1982) Serum antibodies that distinguish between the phospho- and dephospho-form of a phosphoprotein. Nature 299: 734-736.

28. Snyder GL, Girault J-A, Chen JYC, Czernik AJ, Kebabian JW, Nathanson JA, Greengard
P. (1992) Phosphorylation of DARPP-32 and protein phosphatase inhibitor-1 in rat choroid plexus: Regulation by factors other than dopamine. J. Neurosci. 12: 3071-3083.

29. Iverfeldt K, Walaas SI, Greengard P. (1993) Altered processing of Alzheimer amyloid precursor protein in response to neuronal degeneration. Proc. Natl. Acad. Sci. U.S.A. 90: 4146-4150.

30. Wasco W, Gurubhagavatula S, Paradis MD, Romano DM, Sisodia SS, Hyman BT, Neve RL, Tanzi RE. (1993) Isolation and characterization of APLP2 encoding a homologue of the Alzheimer's associated amyloid $\beta$ protein precursor. Nature Genet. 5: 95-100.

31. Drago GA, Colyer J. (1994) Discrimination between two sites of phosphorylation on adjacent amino acids by phosphorylation sitespecific antibodies to phospholamban. J. Biol. Chem. 269: 25073-25077.

32. Lew J, Wang JH. (1994) Neuronal cdc2-like kinase. Trends Biochem. Sci. 20: 33-37.

33. Woodgett JR. (1994) Molecular cloning and expression of glycogen synthase kinase-3/ factor A. $E M B O J$. 9: 2431-2438.

34. Mandelkow E-M, Drewes G, Biernat J, Gustke N, Van Lint J, Vandenheede JR, Mandelkow E. (1992) Glycogen synthase kinase- 3 and the Alzheimer-like state of microtubule-associated protein tau. FEBS Lett. 314: 315-321.

35. Ishiguro $\mathrm{K}$, Shiratsuchi $\mathrm{A}$, Sato $\mathrm{S}$, Omori A, Arioka M, Kobayashi S, Uchida T, Imahori $K$. (1993) Glycogen synthase kinase $3 \beta$ is identical to tau protein kinase I generating several epitopes of paired helical filaments. FEBS Lett. 325: 167-172.

36. Yang S-D, Yu J-S, Shiah S-G, Huang J-J. Protein kinase $\mathrm{F}_{\mathrm{A}}$ /glycogen synthase kinase- $3 \alpha$ after heparin potentiation phosphorylates $\tau$ on sites abnormally phosphorylated in Alzheimer's disease brain. J. Neurochem. 63: $1416-1425$.

37. Shivers BD, Hilbich C, Multhaup G, Salbaum M, Beyreuther K, Seeburg PH. (1988) Alzheimer's disease amyloidogenic glycoprotein: Expression pattern in rat brain suggest a role in cell contact. EMBO J. 7: 13651370.

38. Saitoh T, Sundsmo M, Roch J-M, Kimura N, Cole G, Schubert D, Oltersdorf T, Schenk DB. (1989) Secreted form of amyloid $\beta$ protein precursor is involved in the growth regulation of fibroblasts. Cell 58: 615-622.

39. Araki W, Kitaguchi N, Tokushima Y, Ishii K, 
Aratake H, Shimohama S, Nakamura S, Kimura J. (1991) Trophic effect of beta-amyloid precursor protein on cerebral cortical neurons in culture. Biochem. Biophys. Res. Commun. 181: 265-271.

40. Greenberg SM, Koo EH, Selkoe DJ, Qiu WQ, Kosik KS. (1994) Secreted beta-amyloid precursor protein stimulates mitogen-activated protein kinase and enhances tau phosphorylation. Proc. Natl. Acad. Sci. U.S.A. 91: 71047108.

41. Yoshikawa K, Aizawa T, Hayashi Y. (1992) Degeneration in vitro of post-mitotic neurons overexpressing the Alzheimer amyloid protein precursor. Nature 359: 64-67.
42. Mattson MP, Barger SW, Cheng B, Lieberburg I, Smith-Swintosky VL, Rydel RE. (1993) $\beta$-Amyloid precursor protein metabolites and loss of neuronal $\mathrm{Ca}^{2+}$ homeostasis in Alzheimer's disease. Trends Neurosci. 16: 409-414.

43. Etcheberrigaray R, Ito E, Kim CS, Alkon DL. (1994) Soluble $\beta$-amyloid induction of Alzheimer's phenotype for human fibroblast $\mathrm{K}^{+}$ channels. Science 264: 276-279.

44. Takashima A, Noguchi K, Sato K, Hoshino T, Imahori K. (1993) Tau protein kinase $I$ is essential for amyloid $\beta$-protein-induced neurotoxicity. Proc. Natl. Acad. Sci. U.S.A. 90: 7789-7793.

Communicated by P. Greengard. Accepted on September 20, 1996. 